\title{
The effect of thyroid hormone status on plasma glucose-insulin interrelationship in broiler chickens
}

\author{
J Buyse 1, E Decuypere 1, J Simon 2 \\ 1 Laboratory for Physiology of Domestic Animals, KU Leuven, \\ Kardinaal Mercierlaan 92, 3030 Heverlee, Belgium; \\ 2 INRA, Station de Recherches Avicoles, Nouzilly, 37380 Monnaie, France
}

(Received 6 June 1990; accepted 12 September 1990)

Summary - The aim of the present experiments was to study the plasma glucose-insulin relationship in eu-, hypo- or hyperthyroid broiler chickens. None of the thyroid states modified the fasting plasma glucose and insulin levels. Hypothyroid chickens exhibited a normal glucose tolerance and a normal glucose-induced insulin release after oral glucose $(2 \mathrm{~g} / \mathrm{kg}$ body weight) administration compared to euthyroid chickens. In contrast, hyperthyroid chickens exhibited an improved glucose tolerance accompanied by a lower insulin release. Insulin injections at a concentration of $0.1 \mathrm{U} / \mathrm{kg}$ body weight was only hypoglycemic in hyperthyroid chickens, which confirms the observation that these chickens are more sensitive to insulin. From this study it can be suggested that alterations in body composition according to thyroid status are at least partly mediated by changes in the control of carbohydrate metabolism by pancreatic hormones.

\section{broller / thyroid status / plasma glucose-insulin interrelationship}

Résumé - Effets de l'état thryoïdien sur la relation glycémie-insulinémie chez les poulets de chair. La relation glycémie-insulinémie a été étudiée chez des poulets de chair hyper-, hypo- et euthyroidien. A jeun, l'état thyroïdien ne modifie pas la glycémie ou l'insulinémie. Après une surcharge orale de glucose $(2 \mathrm{~g} / \mathrm{kg})$, les poulets hypothyrö̈diens présentent une tolérance au glucose et une réponse insulinique normale. Par contre, les poulets hyperthyroïdiens ont une meilleure tolérance avec des insulinémies plus faibles. Une injection d'insuline $(0,1 \mathrm{U} / \mathrm{kg})$ n'est hypoglycémiante que chez les animaux hyperthyrö̈diens, confirmant ainsi une sensibilité accrue à l'insuline en cas d'hyperthyroïdisme. Les changements de composition corporelle en fonction de l'état thyroïdien observés chez les poulets de chair sont donc partiellement liés à des modifications du métabolisme glucidique par les hormones pancréatiques.

poulets de chalr / état thyroïdlen / relation plasmatique glucose-insuline

\section{INTRODUCTION}

Thyroid deficiency in the domestic fowl is associated with increased fatness, while hyperthyroidism induced by feeding protamone ( $1 \%$ T4 activity) or by long-term administration of thyroid hormones decreases fat deposition (Wilson et al, 1983;
Decuypere et al, 1987). The decreased fat deposition associated with hyperthyroidism was not proportional in all body fat components, but the observed decreases were percentagewise greatest in abdominal fat, followed by total carcass, thighs and breast muscle fat content, respectively (Decuypere et al, 1989). 
Besides changes induced in circulating levels of growth hormone and somatomedin $\mathrm{C}$ by thyroid status (Decuypere et al, 1987), it was reported that thyroid hormones also influence plasma pancreatic hormone concentrations (Cogburn et al, 1986) and vice versa (Mitchell and Raza, 1986).

Recently it was shown that in 14 weekold White Leghorn cockerels, $T_{4} / T_{3}$ injections reduced glucose-induced insulin concentrations while fasting plasma glucagon levels were elevated (Klandorf, 1988). Whether this is linked with a change in tissue sensitivity to insulin is not known.

In focussing research on thyroid-insulin interaction involvement in adiposity in meat-type chickens an investigation was made into the changes in insulin response upon glucose challenge in long term hypoor hyperthyroid broilers and by the reciprocal test, the glucose response upon insulin challenge.

\section{MATERIALS AND METHODS}

\section{Chickens, housing, management}

Day-old broiler chicks (Hybro) were obtained from a local hatchery and equally divided among 4 floor pens $(1.05 \times 0.77 \mathrm{~m})$. Temperature was set at $30^{\circ} \mathrm{C}$ during the first week and was gradually lowered by $2^{\circ} \mathrm{C}$ per week until a temperature of $20^{\circ} \mathrm{C}$ was reached. The lighting schedule provided $23 \mathrm{~h}$ of light each day, and wood shavings were used as litter.

\section{Diets}

A commercial broiler diet containing $3150 \mathrm{kcal}$ $\mathrm{ME} / \mathrm{kg}$ and $22 \%$ crude protein was supplemented respectively with $0.1 \%$ MMI (2-mercapto-5methylimidazole, methimazole; Janssens Pharmaceutica, Beerse, Belgium) or with $\mathrm{T}_{3}(3,3,5$ -triiodothyronine) at a concentration of $1 \mathrm{ppm}$ (experiments 1 and 2) or $0.5 \mathrm{ppm}$ (experiment 4). Diets were provided ad libitum from day 1 on. Control birds received the basal diet only.

\section{Experimental design}

\section{Experiment 1}

At 5 wk of age, 7 birds in each treatment group were fasted overnight and administered a glucose load of $2 \mathrm{~g}$ per $\mathrm{kg}$ body weight (BW) delivered by intubation in the crop. Just before and 10 , $30,45,60$ and 90 min after the glucose load, a blood sample was taken from a wing vein using a syringe and was transferred to iced tubes. After centrifugation at $4^{\circ} \mathrm{C}$, plasma was frozen until assayed.

\section{Experiment 2}

At 7 wk of age, 9 birds from each treatment group were fasted overnight, then refed for $2 \mathrm{~h}$ before the start of the experiment, in which birds were injected intravenously with $0.1 \mathrm{U}$ insulin (porcine insulin, Actrapid MC, SA Novo Ind, Brussels, Belgium) per kg BW. Birds were bled immediately before and again at 10,30 and 60 min after injection.

\section{Experiment 3}

At 9 wk of age, 10 control and $9 \mathrm{MMl}$-fed birds were fasted overnight and refed for $2 \mathrm{~h}$ before injection. Birds in each treatment group were injected intravenously with $0.5 \mathrm{U}$ insulin per $\mathrm{kg}$ $\mathrm{BW}$, and the other half with an equal volume of physiological solution (saline, $0.9 \% \mathrm{NaCl}$ ). Blood samples were taken prior to and at 10,30 and $60 \mathrm{~min}$ after injection.

\section{Experiment 4}

In this experiment, the same experimental design as in experiment 3 was used but with 8-wk old control birds and birds fed the $0.5 \mathrm{ppm} \mathrm{T}_{3}$ diet.

\section{Assay procedures}

Plasma glucose concentrations were measured according to the method described by Caroll et al (1956). Plasma insulin was measured by radioimmunoassay by using a guinea pig antiporcine insulin serum (Ab 27-6, a gift of G Rosse- 
lin, Hôpital Saint-Antoine, Paris) with chicken insulin as standard, as previously described (Simon et al, 1974).

\section{Statistics}

Plasma glucose and insulin data were analysed by means of multivariate analysis of variance (Manova) with time series as repeated measures [GLM procedure, repeated measures analysis of variance (SAS, 1985)]. For each treatment group separately, plasma variable levels according to time of sampling were contrasted with pretreatment levels using a 1-way Manova with repeated measures (GLM procedure, repeated measures analysis of variance option Contrast transformation). In addition, differences in plasma glucose and insulin concentrations among the treatment groups within each time of blood sampling were analysed by 1-way analysis of variance. Means were contrasted with Duncan's multiple range test.

\section{RESULTS}

\section{Experiment 1}

The effects of an oral glucose (2 $\mathrm{g} / \mathrm{kg} \mathrm{BW}$ ) load on plasma glucose and insulin levels in fasted broilers with different thyroid status are illustrated in figures 1 and 2, respectively.

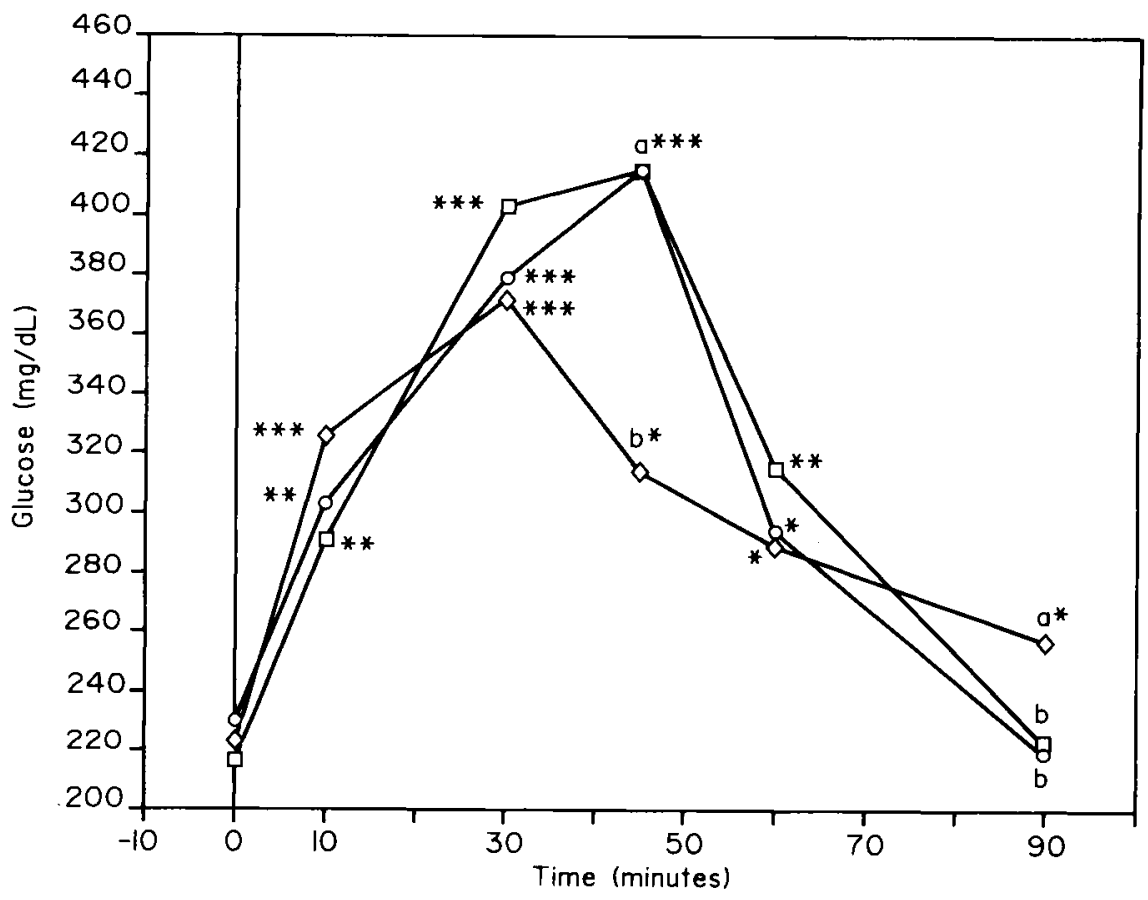

Fig 1. Effect of oral glucose load $(2 \mathrm{~g} / \mathrm{kg} \mathrm{BW})$ to fasted control (D), T3-treated (0) and MM1-treated (O) broilers on mean plasma glucose $(n=7)$. a, b : significant differences $(P<0.05$ between treatment groups at the same sampling time (one-way Anova). ${ }^{*} P<0.05$; ** $P<0.01$; *** $P<0.001$ significance level of difference with pretreatment level for each treatment group separately (one-way Manova for repeated measures). 


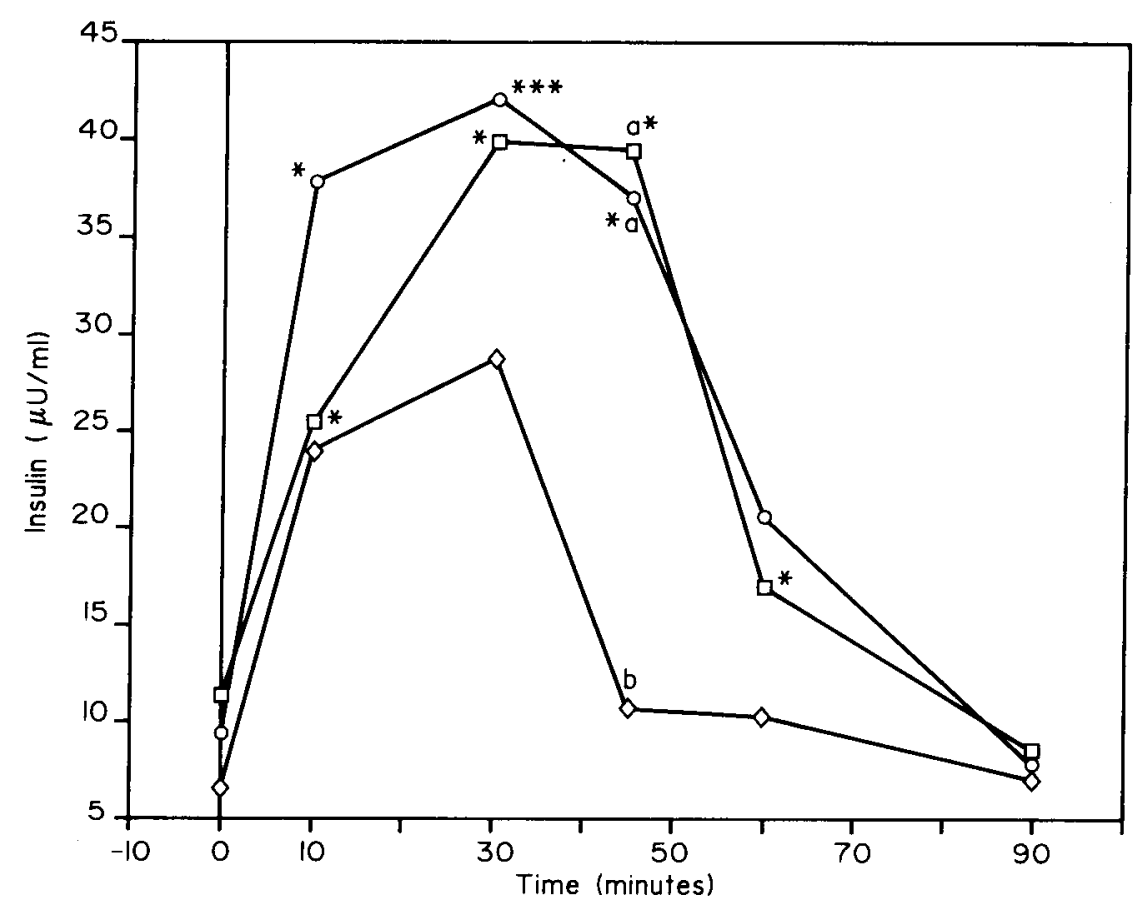

Fig 2. Effect of oral glucose load (2 g/kg BW) to fasted control (D), T3-treated ( 0$)$ and MMI-treated (O) broilers on mean plasma insulin levels $(n=7)$. a, b : See legend to fig 1 ; * : see legend to fig 1 .

No difference in plasma baseline levels for both plasma variables between treatment groups were observed. Oral glucose administration induced a sharp increase in plasma glucose for all groups (fig 1). Multivariate analysis of variance for repeated measures revealed a significant effect of time $(P<0.0001)$ and time $x$ treatment group $(P<0.05)$ interaction. This interaction indicated a treatment group dependent plasma glucose disappearance pattern. At 45-min post-administration, plasma glucose levels in the $T_{3}$-fed birds had already declined and were significantly lower compared with both other treatment groups. At $90 \mathrm{~min}$ however, the mean plasma glucose level of hyperthyroid birds was significantly higher compared to both other treatment groups and remained higher than the fasting level.

For the plasma insulin data (fig 2), a significant time $(P<0.0001)$ and treatment group effect $(P<0.01)$ was calculated. In MMI-fed and control birds, plasma insulin levels were significantly increased $10 \mathrm{~min}$ after the glucose load and remained high until 45 min post-treatment. Although the mean plasma insulin level of $T_{3}$-fed birds was also apparently increased at 10 and $30 \mathrm{~min}$, differences were not statistically discernable at the $5 \%$ level from the pretreatment level. At $45 \mathrm{~min}$, the mean plasma insulin level was significantly lower in the $T_{3}$-fed group compared to both other groups. 


\section{Experiment 2}

In this experiment, the effect of an intravenous injection of $0.1 \mathrm{U}$ insulin per $\mathrm{kg} \mathrm{BW}$ on plasma glucose levels was compared between the treatment groups (fig 3). Manova using data of all groups revealed a significant time $(P<0.0001)$ and group $(P<$ 0.01 ) effect. When performing a 1-way Manova to glucose data of the groups separately, a significant time effect $(P<0.0001)$ was only present for the $T_{3}$-fed group. A significant decline in plasma glucose was already noticable at $10 \mathrm{~min}$ and persisted at $30 \mathrm{~min}$ post-injection. For the MMl-fed chickens, plasma glucose concentrations at $\mathbf{3 0} \mathrm{min}$ post-injection were significantly lower than the corresponding level in control birds but not significantly different compared to pre-treatment values.

\section{Experiment 3}

The comparison of the glucose response curves in a 2-factor Manova for repeated measures revealed a significant effect of time $(P<0.001)$ and a time $x$ injection treatment (saline or insulin) effect, indicating that the plasma glucose levels were only affected when insulin was administered exogenously (fig 4). Iv injection of 0.5 $\mathrm{U}$ insulin per $\mathrm{kg}$ BW depressed plasma glucose values in control birds within 10 $\min$. At this time, plasma glucose level for the MMI-fed birds were also apparently re-

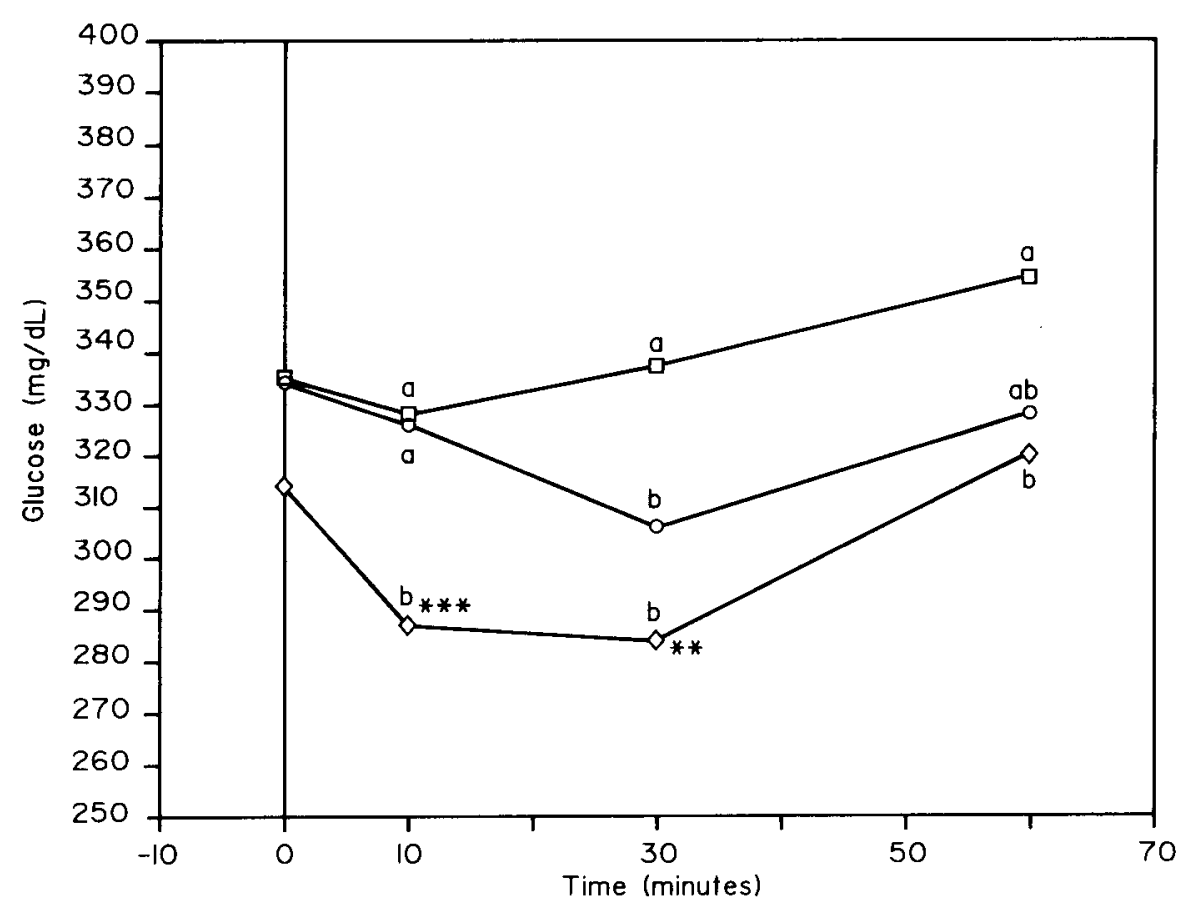

Fig 3. Effect of iv injection of $0.1 \mathrm{U}$ insulin $/ \mathrm{kg} \mathrm{RW}$ to fed control (D), T3-treated $(0)$ and MMI-treated (O) broilers on plasma glucose levels $(n=9)$. a, b: See legend to fig $1 ;{ }^{*}:$ See legend to fig 1 . 


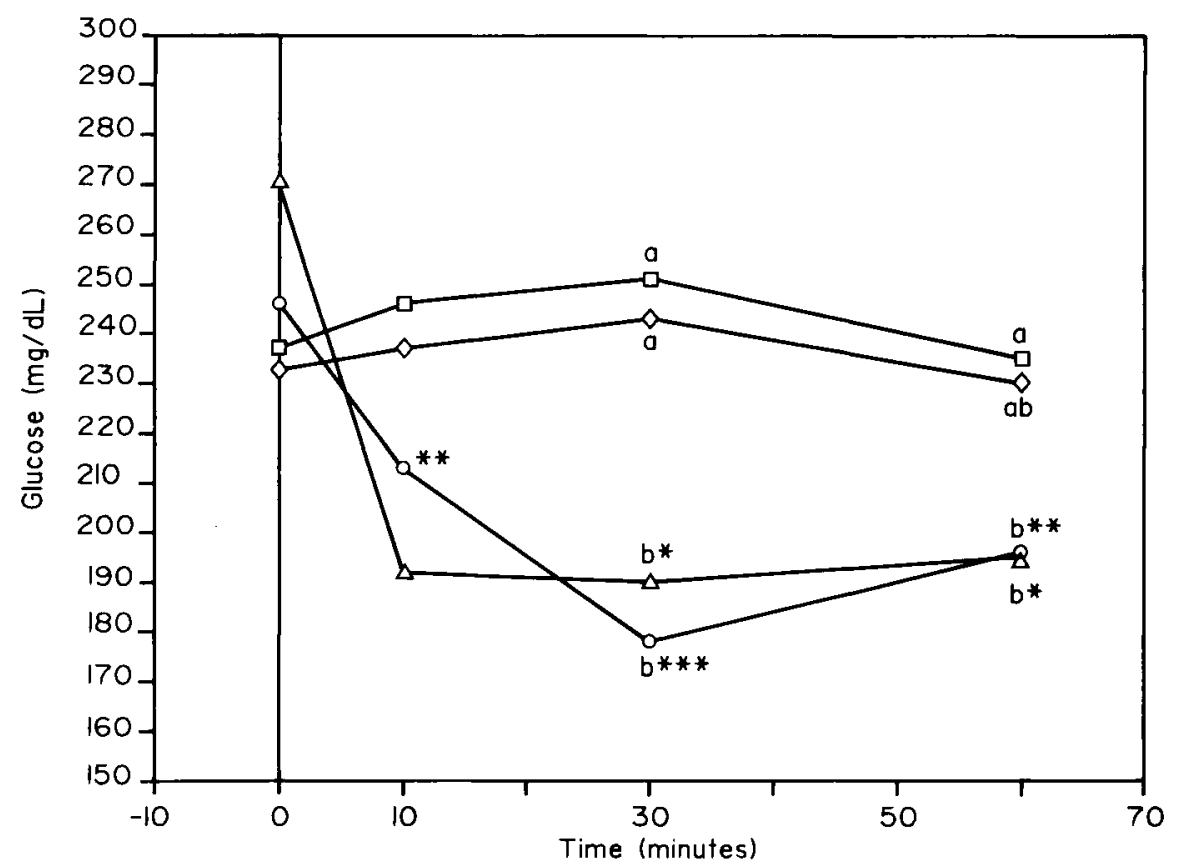

Fig 4. Effect of IV injection of $0.5 \mathrm{U}$ insulin/kg BW to fed control $(0)$ and MMI-treated $(\Delta)$ broilers or an equal volume of saline to control $(\square)$ and MMI-treated $(0)$ broilers, on plasma glucose levels $(n=4-5)$. $a, b$ : See legend to fig $1 ; "$ : See legend to fig 1 .

duced, but not statistically discernable $(P=$ $0.054)$. For both groups, plasma glucose levels remained low for the duration of the sampling period.

\section{Experiment 4}

Two-factor Manova revealed a significant time effect $(P<0.05)$, but only when insulin was administered. No statistically signi-. ficant differences between control and $\mathrm{T}_{3^{-}}$fed chickens were found either after saline injection or in pretreatment glucose level (fig 5). Iv injection of $0.5 \mathrm{U}$ insulin per $\mathrm{kg}$ BW significantly depressed plasma glucose levels in $T_{3}$-fed birds within $10 \mathrm{~min}$ compared with the pretreatment level and with the saline-injected counterparts. For the control birds, the glucose level $10 \mathrm{~min}$ after insulin administration was not significantly different at the $5 \%$ level either from pretreatment level $(P=0.069)$ or from the saline-injected control group. At $30 \mathrm{~min}$ and at $60 \mathrm{~min}$, plasma glucose levels were significantly depressed in both treatment groups.

\section{DISCUSSION}

The aim of the present experiments was to study the plasma glucose-insulin relationship in either hypo- or hyperthyroid broiler chickens. 


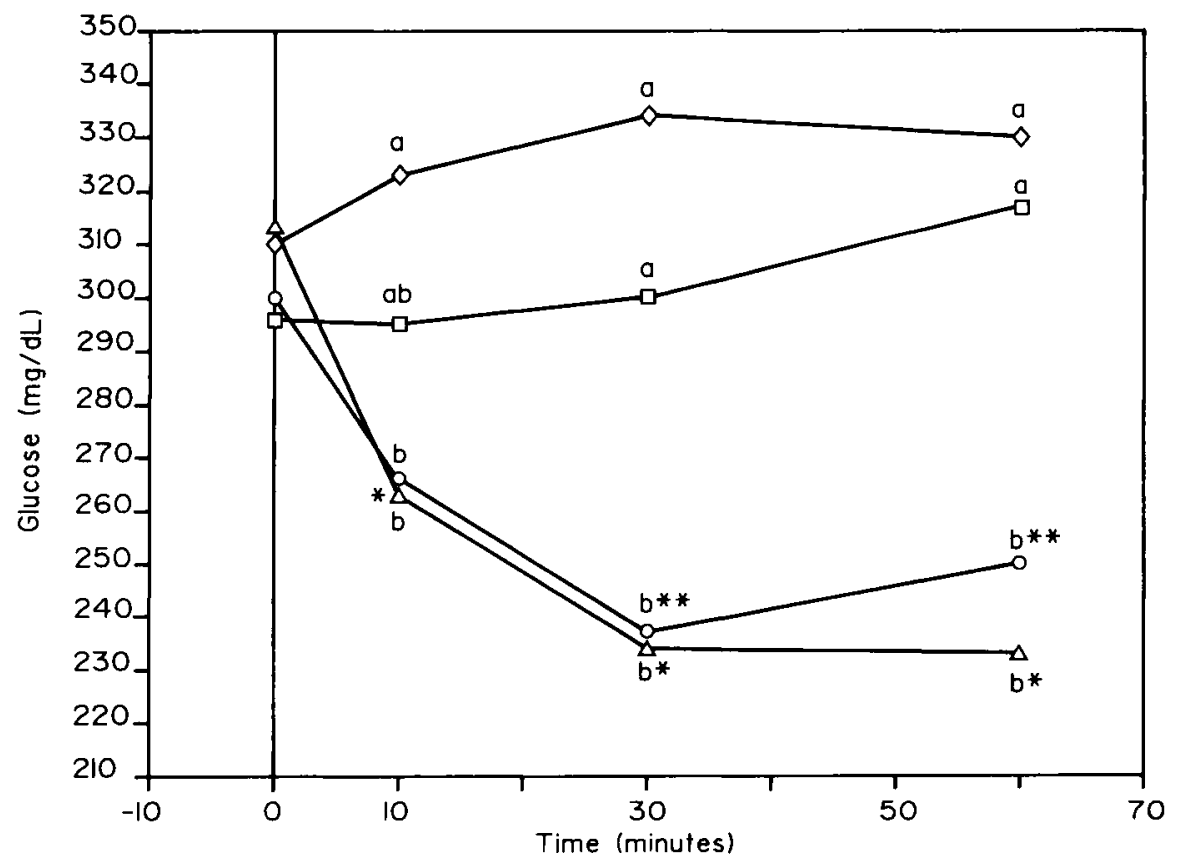

Fig 5. Effect of iv injection of $0.5 \mathrm{U}$ insulin $/ \mathrm{kg} \mathrm{BW}$ to fed control $(O)$ and T3-treated $(\Delta)$ broilers or an equal volume of saline to control $(\square)$ and T3-fed $(0)$ broilers, on plasma glucose levels $(n=5)$. a,b : see legend to fig $1 . "$ : see legend to fig 1.

Although fasting resulted in decreased plasma glucose values as well as in decreased $T_{3}$ levels as a consequence of a decreased peripheral $T_{4}$ into $T_{3}$ conversion (Decuypere and Kühn, 1984), a long-term change in thyroid status did not modify the fasting plasma glucose and insulin concentrations. In contrast, Klandorf (1988) observed significant alterations in fasting plasma insulin levels in White Leghorn chickens according to their thyroid status.

Whereas the peak of hyperglycemia was observed 10 min after intravenous glucose injection by Klandorf (1988), in our experiment peak levels were only observed after $45 \mathrm{~min}$ in control and hypothyroid birds. The way of glucose administration is responsible for the shift in occurrence of the glucose peak, as shown by Klandorf (1988). In our experiment, the disposal of an oral glucose load was clearly accelerated at $45 \mathrm{~min}$ in the hyperthyroid birds. This is in contrast with the impairment of glucose tolerance in hyperthyroid mammals (Lenzen and Bailey, 1988). Hyperthyroidism affected the course of glucose disappearance in our experiment, while this was not apparent in the data of Klandorf (1988). This is most likely accounted for by the fact that in the experiments of Klandorf (1988) glucose was administered intravenously, which caused a very rapid disappearance of glucose. However, in both studies after the initial plasma-glucose decline, glucose levels of hyperthyroid 
birds remained high compared to pretreatment levels and to other treatment groups.

In $T_{3}$-treated chickens, the improvement of glucose tolerance is associated with slightly lower insulin levels at $\mathbf{3 0} \mathrm{min}$ and a rapid normalization at $45 \mathrm{~min}$. The fact that insulin increased only during a short time following glucose load in $\mathrm{T}_{3}$-treated broiler chickens is in accordance with the results observed in hyperthyroid White Leghorn chickens following intravenous glucose load (Klandorf, 1988). The rapid disposal of glucose most likely accounts for the shorter duration of insulin release in hyperthyroid chickens. It would not result from the decreased feed transit time which was observed in $\mathrm{T}_{4^{-}}$or $\mathrm{T}_{3}$-treated chickens (Decuypere and Siau, 1990) since glucose was taken up rapidly (10 and $30 \mathrm{~min}$ ) and totally from the intestine and resulted in high plasma leveis at an equally early time after ingestion in all groups.

Despite the fact that the chicken is relatively resistant to insulin compared to mammals, insulin sensitivity in chickens may also be modified by nutritional or genotypic factors (Simon, 1989). The rapid glucose disposal and low insulin levels in hyperthyroid broilers suggests a state of increased insulin sensitivity. This was effectively observed in experiment 2 where $0.1 \mathrm{U}$ insulin/kg had a hypoglycemic effect only in hyperthyroid chickens. Furthermore, it is also possible that the high plasma levels of $T_{3}$ in $T_{3}$ supplemented broiler chickens (Decuypere et al, 1987) may increase glucose transport in insulin sensitive tissues. Such a positive synergy has been observed in isolated chicken embryo heart cells (Gordon et al, 1986).

As hyperthyroidism is associated with an increased metabolic rate, it is very likely that the available glucose is removed very rapidly from the glucose pool by means of enhanced transport in tissues and readily oxidized to maintain the high metabolic rate.

Hypothyroid chickens exhibited a normal glucose tolerance. The glucoseinduced insulin release is rapid and slightly increased at $10 \mathrm{~min}$ compared to both other treatment groups. Therefore, hypothyroidism would increase insulin levels in chicken. In our MMI-treated chickens, the enhancement of plasma insulin levels is, however, less marked than in thyroidectomized (Klandorf, 1988) or in PTU-treated White Leghorn chickens (Raheja et al, 1980).

In the present study, insulin sensitivity was similar in hypothyroid and in control chickens. Therefore, it is possible that the enhanced insulin levels in hypothyroid accounts for their enhanced fatness (Decuypere et al, 1987). Insulin is effectively lipogenic in chicken hepatocytes (reviewed by Simon, 1989). In addition, the lipogenic effect of insulin may be further potentiated by a decrease in plasma glucagon levels as observed in PTU-treated White leghorn chickens (Raheja et al, 1980).

Whether glucagon sensitivity is dependent upon thyroid state remains unknown. This is currently under investigation in vitro using adipocytes isolated from eu-, hyperand hypothyroid chickens.

When increased fat deposition induced by hypothyroidism or due to selection is compared with respect to the plasma glucose-insulin interrelationship, some aspects are changed in a similar manner such as the enhanced glucose-induced insulin levels in fat birds (reviewed by Simon, 1988). On the other hand, some discrepancies can be observed which do not allow equalizing of the selection effect with the effect of altered thyroid state to a parallel change in carbohydrate metabolism. Genetically fat chickens, compared to their lean counterparts, are slightly hypo- 
glycemic, exhibit an improved glucose tolerance and are more sensitive to exogenous insulin at least in the fasted state (Simon, 1988, 1989). In contrast, our "fat" hypothyroid chickens were less sensitive to exogenous insulin and exhibited an impaired glucose tolerance compared to hyperthyroid chickens. Moreover, even though plasma $T_{3}$ levels are slightly lower in genetically fat chickens, dietary $T_{3}$ supplementation which permits nearnormalization of plasma $T_{3}$ levels, has minimal effect on the difference between the 2 lines in fat content (Leclercq et al, 1988).

From the results reported herein and those obtained in genetically fat chickens, it is suggested that in chickens, alterations in body composition according to thyroid status or by means of selection, are at least partly mediated by changes in the control of carbohydrate metabolism by pancreatic hormones.

\section{ACKNOWLEDGMENTS}

The excellent technical assistance of $K$ Devos, $G$ Witvrouw and $M$ Derouet is gratefully acknowledged.

\section{REFERENCES}

Caroll NV, Longley RW, Roe JH (1956) The determination of glycogen in liver and muscle by use of anthrone reagent. $J$ Biol Chem 220 , 583-593

Cogburn LA, Liou SS, McMurtry JP (1986) Plasma levels of insulin and glucagon in broiler chickens fed thyroid-active substances. Poult Sci 65, 27 (abstract)

Decuypere E, Kühn ER (1984) Effect of fasting and refeeding time on circadian rhythms of serum thyroid hormone concentrations, glucose, liver monodeiodinase activity and rectal temperature in growing chickens. Domest Anim Endocrinol 1, 251-262
Decuypere E, Siau O (1990) Food, hormones, growth and their relationship. In: Trends and Developments in the Feed Industry, Proc Int Symp Athens 1989, 77-87

Decuypere E, Buyse J, Scanes CG, Huybrechts L, Kuhn ER (1987) Effects of hyper- or hypothyroid status on growth, adiposity and levels of growth hormone, somatomedin C and thyroid metabolism in broiler chickens. Reprod Nutr Dev 27, 555-556

Decuypere E, Devos K, Bergman L, Darras VM, Vandesande F, Kuhn ER (1989) Influence of thyroid state on adiposity, growth hormone (GH) levels and on TRH- or GRF-induced GH-release in broilers. In: Endocrinology of Farm Animals (K Boda ed) Academy of Sciences, Kosice (Czechoslovakia) 375-381

Gordon A, Schwartz H, Gross J (1986) The stimulation of sugar transport in heart cells grown in a serum-free medium by picomolar concentrations of thyroid hormones: the effects of insulin and hydrocortisone. J Endocrinol 118, 52-57

Klandorf $H$ (1988) Glucose tolerance and pancreatic hormones in thyroidectomized and thyroid hormone-injected cockerels. Gen Comp Endocrinol 69, 226-232

Leclercq B, Guy G, Rudeaux F (1988) Thyroid hormones in genetically lean or fat chickens: effects of age and triiodothyronine supplementation. Reprod Nutr Dev 28, 931-937

Lenzen S, Bailey C (1984) Thyroid hormones, gonadal and adreno-cortical steroids and the function of the islets of Langerhans. Endocr Rev 5, 411-434

Mitchell MA, Raza A (1986) The effects of glucagon and insulin on plasma thyroid hormone levels in fed and fasted domestic fowls. Comp Biochem Physiol 85A, 217-223

Raheja KL, Linscheer WG, Coulson R, Wenthworth S, Pineberg SE (1980) Elevated insulin glucagon ratios and decreased cyclic AMP levels accompany the glycogen and triglyceride storage syndrome in the hypothyroid chick. Horm Metab Res 12, 51-55

SAS Inst Inc (1985) SAS/STAT. Guide for Personal Computers, Version 6 Cary, NC: Inst Inc, $378 \mathrm{p}$

Simon J (1988) Insulin in birds: metabolic effects and possible implications in genetically fat and lean chickens. In: Leanness in Domestic Birds: Genetic, Metabolic and Hormo- 
nal aspects. (Leclercq B, Whitehead CC, eds) Butterworths, London 253-268

Simon J (1989) Chicken as a useful species for the comprehension of insulin action. CRC Crit Rev Poult Biol 2, 121-148

Simon, J, Freychet P, Rosselin G (1974) Chicken insulin: radioimmunological characteriza- tion and enhanced activity in rat fat cells and liver plasma membranes. Endocrinology 95, 1439-1449

Wilson HR, Boone MA, Arafa AS, Janky DM (1983) Abdominal fat pad reduction in broilers with thyroactive iodinated casein. Poult Sci $62,811-818$ 